\title{
ADAPTED QUADRATIC APPROXIMATION FOR SINGULAR INTEGRALS
}

\section{MOSTEFA NADIR}

Abstract. The goal of this work is to present an adapted modification to the parabolic approximation of the density function for singular integrals of Cauchy type. This approximation serves to eliminate the singularity of the integral and gives the help to obtain the numerical solution of singular integral equations with Cauchy type kernel on an oriented smooth contour.

Mathematics subject classification (2010): Primary 45D05, 45E05, 45L05; Secondary 65R20. Keywords and phrases: Singular integral, quadratic interpolation, Hőlder space, Hólder condition.

\section{REFERENCES}

[1] D. J. AnTIDZE, On the approximate solution of singular integral equations, Seminar of Institute of Applied Mathematics, 1975, Tbilissi.

[2] N. I. MuskHelishvili, Singular integral equations, Naukah Moscow, 1968, English transl, of 1sted Noordho, 1953; reprint, 1972.

[3] M. NADIR, Problèmes aux limites qui se reduisent aux equations intégrales de Fredholm, Seminaire de l'Institut de Mathématiques et Informatique, 1985, Annaba.

[4] M. NADIR, Opérateurs intégraux et bases d'ondelettes, Far East J.Sci., 6, 6 (1998), 977-995.

[5] M. NADIR, J. ANTIDZE, On the numerical solution of singular integral equations using Sanikidze's approximation, Comp Meth in Sc. Tech., 10, 1 (2004), 83-89.

[6] M. NADIR, B. LAKEHALI, On The Approximation of Singular Integrals, FEN DERGİSİ (E-DERGI), 2, 2 (2007), 236-240.

[7] J. SANIKIDZE, On the approximate calculation of singular line integral, Seminar of Institute of Applied Mathematics, 1970, Tbilissi.

[8] J. SANIKIDZE, Approximate solution of singular integral equations in the case of closed contours of integration, Seminar of Institute of Applied Mathematics, 1971, Tbilissi. 